\title{
ON THE EVALUATION OF GNSS COMPLEMENTARY BY USING QUASI-ZENITH SATELLITE OF JAPAN
}

\author{
N.Sekiguchi ${ }^{\mathrm{b}}$,M.Shikada ${ }^{\mathrm{a}}$ and T.Kanai ${ }^{\mathrm{a}}$ \\ ${ }^{a}$ Dep. of Civil and Environmental Engineering, Kanazawa Institute of Technology, 7-1 Ohgigaoka Nonoichi City ,921-8501 Japan \\ shikada@neptune.kanazawa-it.ac.jp \\ ${ }^{\mathrm{b}}$ East Japan Railway Company, 2-2-2,Yoyogi,Shibuyaku,Tokyo Japan
}

Commission I, WG I/5

KEY WORDS: GNSS, QZS, GNSS Complementary, GNSS Augmentation

\begin{abstract}
:
The positional information has an important role in our life-style. People need to get positional information by GNSS. The satellite positioning must receive a signal from four or more satellites, however, most of Japanese country is covered with mountain and urban area has a lot of tall buildings. Then Japanese government launched QZS (Quasi - Zenith Satellite) which is the first satellite of QZSS (Quasi - Zenith Satellite System) in 2010. QZSS including QZS can improve positioning accuracy and reliability. QZS has 6 signals by using four kinds of frequency. These signals are the same frequency of GPS and GLONASS and so on. This paper was reported about the comparison of the positioning between GPS and QZSS.
\end{abstract}

\section{INTRODUCTION}

GNSS positioning technology already has important role in our life-style. People must obtain positional information by GNSS including GPS. The satellite positioning must receive a signal from four or more satellites, however, most of Japanese country is covered with mountain and urban area has a lot of tall buildings. This is one of the reasons why we cannot obtain the exact position information by multipath and cycle slip and other noise. Then the Japanese government launched Quasi-Zenith Satellite (QZS) to get the practical application of QuasiZenith Satellite and the experiment has been performing all over Japan. At the present time, we have only a zenith satellite which was named "MITIBIKI". However, Japanese government has already decided to launch seven satellites in until by 2018. After seven satellites are arranged, at least one satellite is in the zenith in Japan. At the end of 2010s, a satellite will always be in the zenith, and accurate position information is acquired for 24 hours. We conducted an experiment of only GPS positioning and GPS positioning including QZS. This paper describes the GPS positioning result including the signals from QZS.

Table 1. Margin settings for A4 size paper

\begin{tabular}{|c|c|c|c|c|}
\hline signal & Center frequency & channel & & \\
\hline L1C/A signa* $*$ & \multirow{4}{*}{$1575.42 \mathrm{MHz}$} & \multirow{3}{*}{ IPM } & I & - \\
\hline \multirow{2}{*}{ L1C signal* } & & & 1 & Date \\
\hline & & & $\mathrm{Q}$ & Pilot \\
\hline L1-SAIF signal & & \multicolumn{3}{|l|}{ BPSK } \\
\hline LEX signal & $1278.75 \mathrm{MHz}$ & \multicolumn{3}{|l|}{ BPSK } \\
\hline L2C signal* & $1227.60 \mathrm{MHz}$ & \multicolumn{3}{|l|}{ I-channel } \\
\hline L5 signal* & $1176.45 \mathrm{MHz}$ & \multicolumn{3}{|l|}{ Q-channel } \\
\hline
\end{tabular}

IPM: Inter plex Moducation

*Compatible with GPS

\section{QZSS (QUASI-ZENITH SATELLITES SYSTEM)}

QZSS is the satellite system which combined plural satellites with the special orbit in Japan which passes along the zenith. In order that the orbit of QZS might stay at the zenith in Japan for a long time, the orbit of the asymmetrical character of 8 was adopted. QZSS transmits six kinds of QZS signals using four kinds of frequency. Figure 1 shows Quasi-Zenith Satellite orbit.

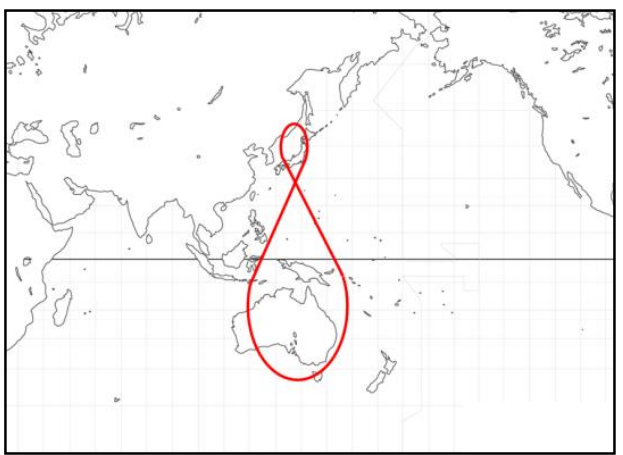

Figure1 Orbit of Quasi-Zenith Satellite

QZS has 2 functions, which are GNSS augmentation and GNSS complementary. First of all, the augmentation of GNSS which is transmitting a high accuracy correction signal from QZS can be able to collect high accuracy positioning. The second is to increase time it's possible to use a QZSS satellite. Signals sent from high elevation angle will increase the receivable number of satellites, and improve a satellite constellation. QZS was designed to supplement the performance of GNSS use by Japan (JAXA). It is the compatible signals of L1C, L2C and L5 to the future GNSS. Table 1 shows the signal of QZS. Integrated use of GPS and QZSS is expected to significantly improve the performance of satellite navigation in Japan and neighboring parts of Asia. Especially in urban canyons and mountainous areas, as QZSS satellites will be seen at very high elevation angles in those regions. 


\section{OUTLINE OF EXPERIMENT}

The experiment was carried out at the rooftop of No.3 building in Ohgigaoka campus of the Kanazawa Institute of Technology. The receivers were used JAVAD TR_G3T ALPHA. Fixed point observation was performed by two receivers. Sky of the experiment location is opening. Figure 2 shows the experimental location. The experiment performs only time zone of more than 50 degrees elevation angle of the QZS, we performed mainly experiments at more than 75 degrees. Observational time is 2 hours per one experiment. Analysis has been used by RTKLIB 2.4.2. We carried out Static positioning using the GNSS-based control stations by this software. We performed two type experiment that use the "GPS" only, and "GPS and QZSS." Positional effect of the signal from QZS was investigated. The purpose of the experiment is a pre-research and positioning accuracy evaluation of the variation of the positioning time due to the quasi-zenith satellite is added.

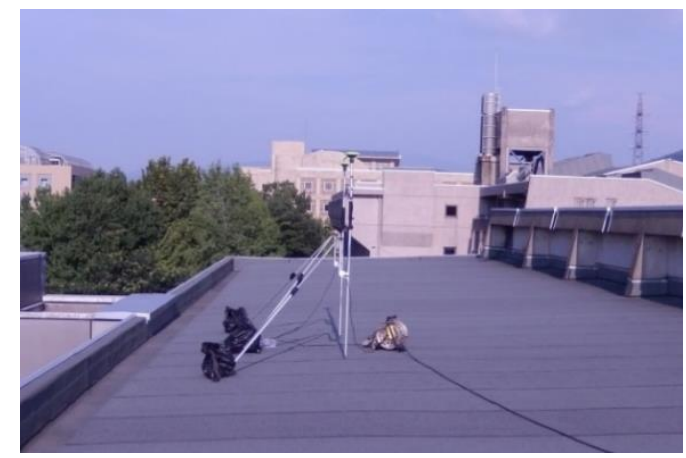

Figure 2 Experimental location

\section{RESULTS OF EXPERIMENT}

\subsection{Results of Positioning}

Figure 3 and Figure 4 show the maximum value, minimum value, average value of north-south direction and east- west direction from each positioning systems in observation time. Vertical axis is the coordinates of Japan and the horizontal axis is an experimental number. The largest value is north direction, and the minimum value is south direction in Figure 3. Figure 4 indicated the largest value is east direction, and the minimum value is west direction.

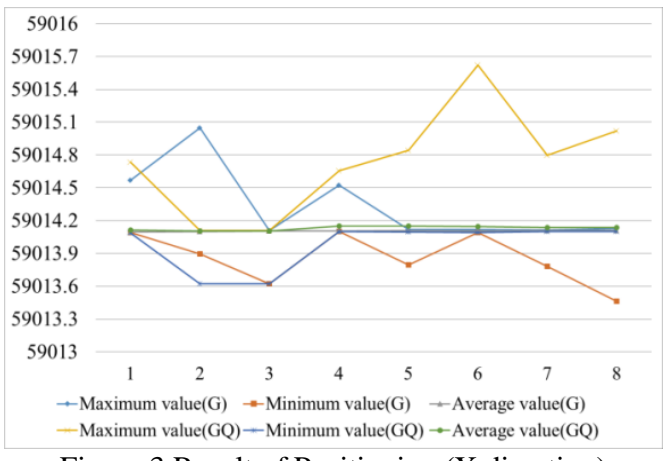

Figure 3 Result of Positioning (X direction)

Figure 3 indicated the maximum of north direction was result of GPS plus QZSS positioning. Also, maximum of south direction were result of GPS positioning. Average value of the two type's position was almost the same level.

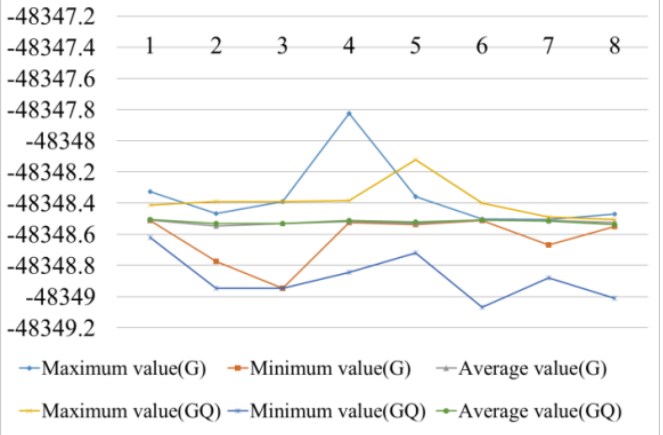

Figure 4 Result of Positioning (Y direction)

Figure 3 indicated the maximum of north direction was result of GPS plus QZSS positioning. Also, maximum of south direction were result of GPS positioning. Average value of the two type's position was almost the same level.

Figure 4 indicated the maximum value is the GPS positioning result is in the east direction. The maximum value of west direction is GPS plus QZSS positioning, and average value of the two positioning was almost the same level. Average value of each position was same level in all directions.

Figure 5 and 6 shows the HDOP and average value. Left and right axis shows Japanese coordinate system and value of HDOP respectively.

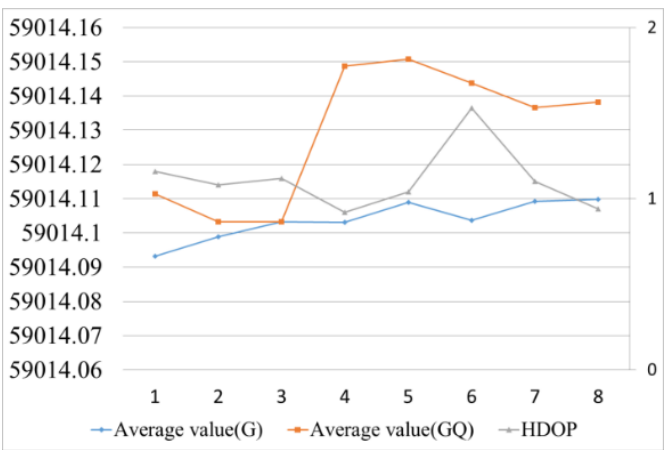

Figure 5 Average value of the experimental results and the HDOP (X direction)

Figure 5 indicated average value of the GPS positioning had fluctuation of about $4 \mathrm{~cm}$. The average value of GPS plus QZSS is changing about $5 \mathrm{~cm}$ in experiment No.3. The cause of activity is not clear at present.

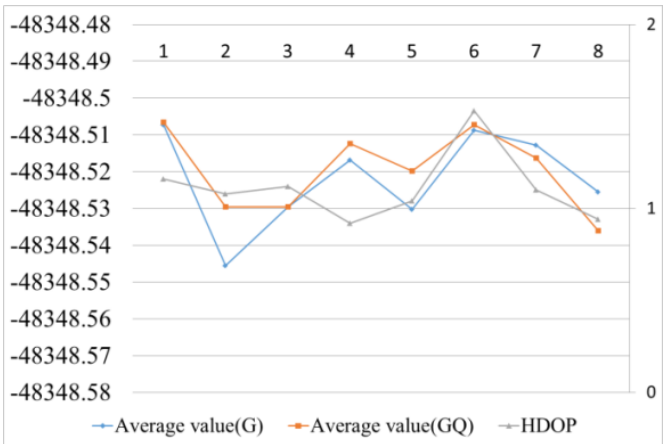

Figure 6 Average value of the experimental results and the HDOP (Y direction)

Figure 6 indicated each positioning had were both similar changes in the east-west direction. Relationship between HDOP and positioning changes, it was not seen in those figure. 


\subsection{Experimental result of positional time}

Then, it was carried out static positioning for investigate to surveying time by setting the different mask angle of satellite elevation. Verification is simulated by using a function of the mask elevation (not using the below elevation angle the satellite to the positioning) of RTKLIB version.2.4.2, it was investigated by increasing or decreasing the mask elevation. Figure 7 is outline of mask condition. Mask angle varies from 30degrees to 60degrees.

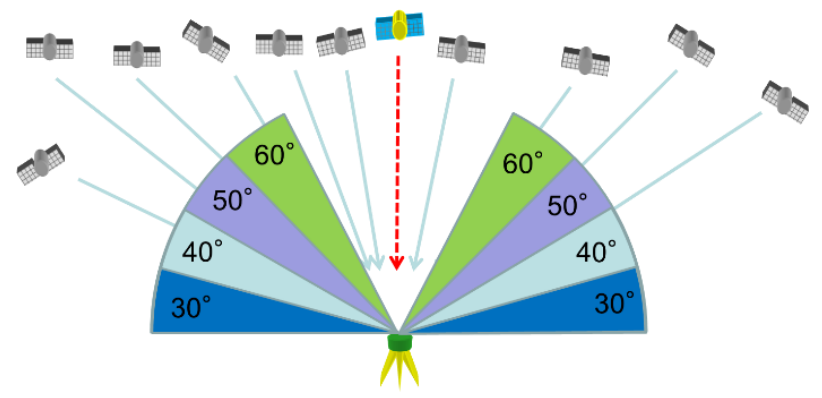

Figure 7 Outline of Mask

From Figure 8 to Figure10 indicates the condition of the mask analysis from $30^{\circ}$ to $60^{\circ}$. Conditions are FIX, FLOAT, and number of satellite and positioning of GPS, GPS + GZSS. The vertical axis is difference from average of positioning, the horizontal axis is observation time.

In Figure 8(mask is 30 degree), measuring condition using GPS+QZSS has not stable until 30 minutes from start time, however, GPS has a good condition from starting time. At least GPS measure has 4 satellite, but it can get positioning. GPS+QZSS shows FLOAT in beginning time. In Figure 9(mask is 40 degree), GPS+QZSS does not stable until 75 minutes from measurement were starting. GPS has stable from starting time. GPS has only FIX but GPS+QZSS has FLOAT as a long time. In Figure 10(mask is 50 degree), only GPS using condition is not stable until 90 minute from start time, however, GPS+QZSS has a stable measuring condition.

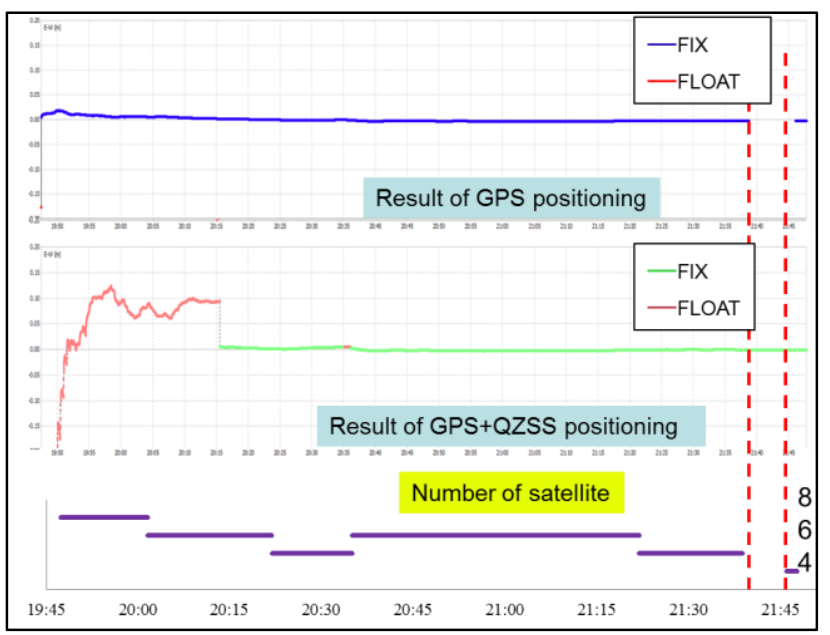

Figure 8 Relation between FIX and FLOAT with GPS, GPS+QZSS and number of satellite at mask $30^{\circ}$

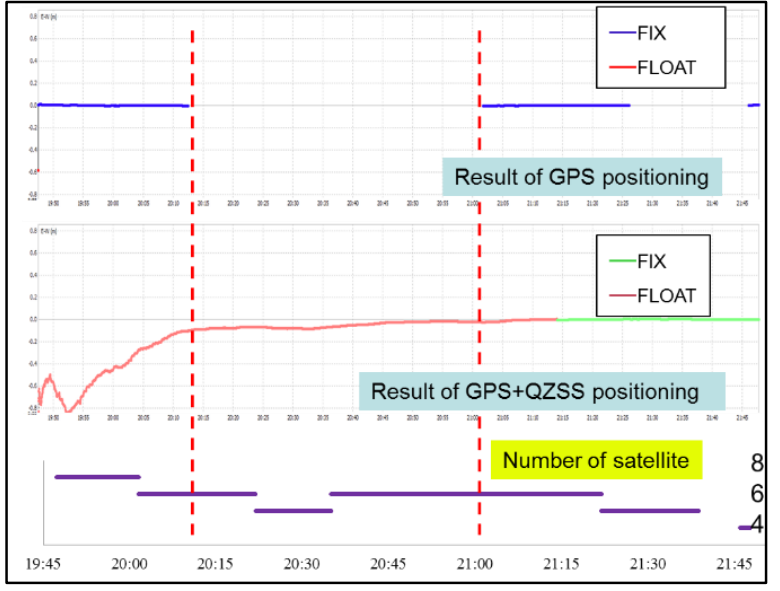

Figure 9 Relation between FIX and FLOAT with GPS, GPS+QZSS and number of satellite at mask $40^{\circ}$

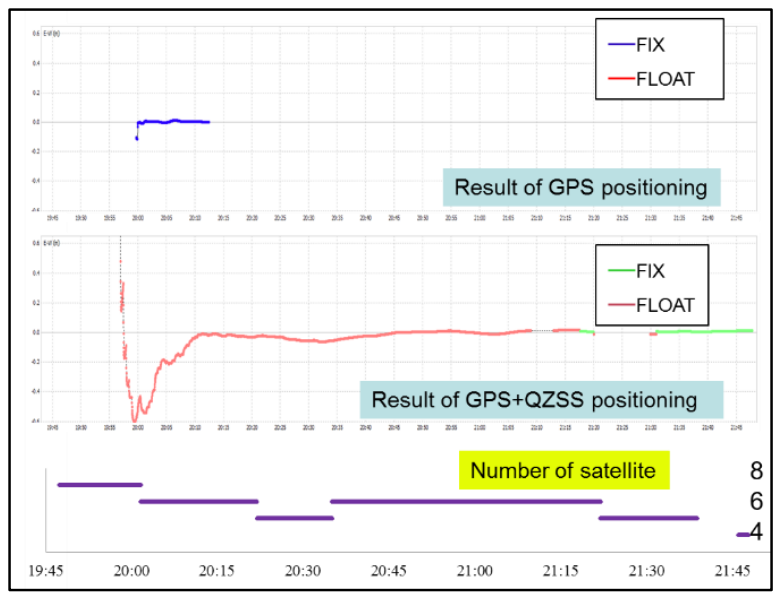

Figure 10 Relation between FIX and FLOAT with GPS, GPS+QZSS and number of satellite at mask $50^{\circ}$

From Figure 11 to Figure 14 indicates the results of the mask analysis about $40^{\circ}, 50^{\circ}$ and $60^{\circ}$. Experiments was carried out on April 19, 2015 by cardinal direction. The vertical axis is a Japanese coordinate systems, the horizontal axis is time (UTC). The satellite condition was indicated on each Figures.

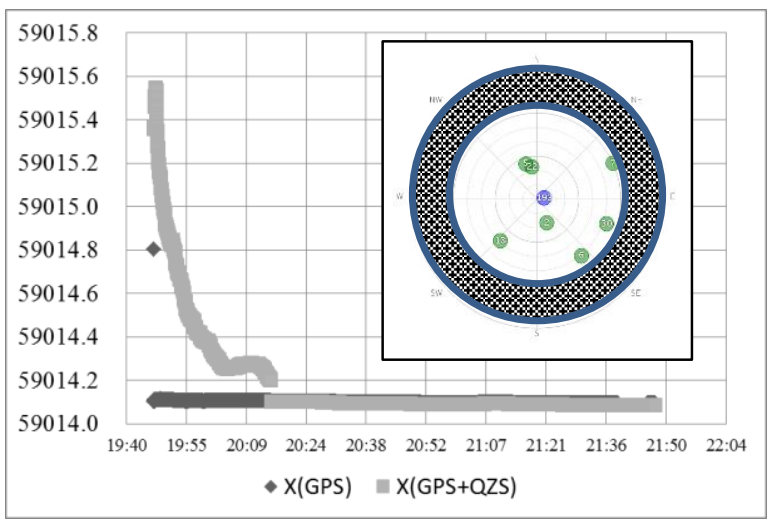

Figure 11 Mask angle is 30 degrees (X direction) 


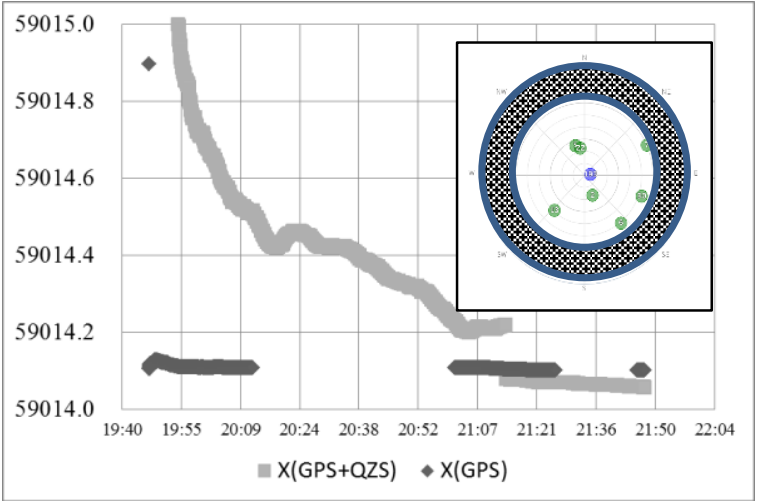

Figure 12 Mask angle is 40 degrees (X direction)

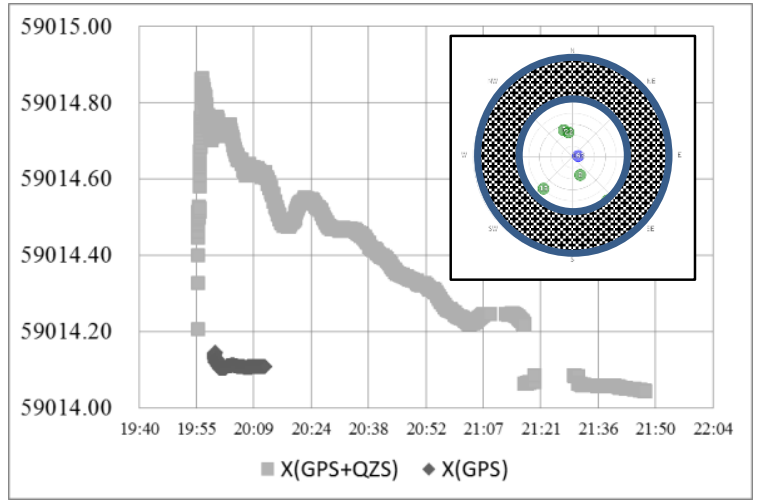

Figure 13 Mask angle is 50 degrees (X direction)

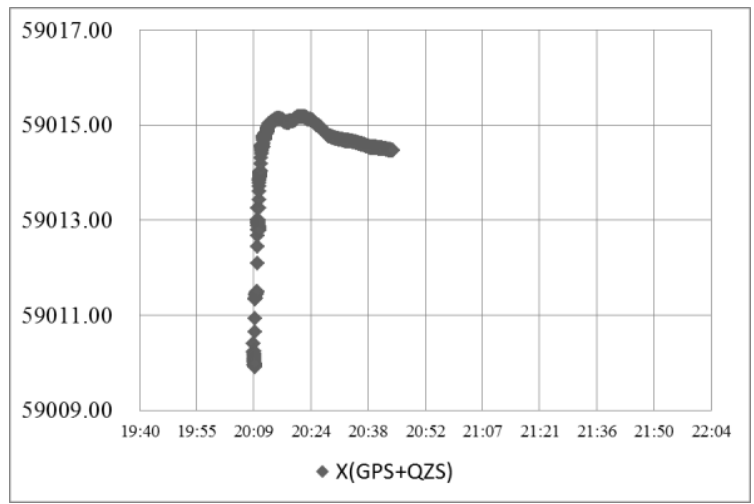

Figure14 Mask angle is 60 degrees

These figures indicates the results of the mask analysis. From these figure, positioning time was clearly reduced as it increases the elevation mask. In the case of 60 degrees, GPS positioning could not get position. Positioning including the QZS did not decrease possible time of measuring until 40 degrees. Also, it was possible to get position until elevation mask is 60 degrees. Stable positioning including the QZS needs a lot of time. The initial solutions may affect the average value and standard deviation. When it is impossible to obtain a solution in the positioning of only GPS, QZS is very important. Table 3 indicated the positional possible hour every 5 degrees over 30 degrees. These data were carried out in April 19, 2015.

\begin{tabular}{|l|l|l|r|r|r|r|r|}
\hline $4 / 19 \mathrm{a}$ & $30^{\circ}$ & $35^{\circ}$ & $40^{\circ}$ & $45^{\circ}$ & $50^{\circ}$ & $55^{\circ}$ & $60^{\circ}$ \\
\hline $\mathrm{G}$ & 6785 & 6161 & 3071 & 2013 & 766 & 136 & 0 \\
\hline $\mathrm{G}+\mathrm{Q}$ & 7221 & 7221 & 7221 & 6986 & 5910 & 3673 & 2095 \\
\hline
\end{tabular}

Table 3 Result of positional time (s)
From Table 3, trend of positioning time is decreasing as increase the elevation mask angle. As the reason of its, minimum required number of satellites was insufficient when elevation mask angle is increasing. Table 3 shows just the elevation mask was 30 degrees, there was no change in the positioning time. At elevation mask over 45 degrees, GPS positioning was impossible. In both experiments, QZSS positioning including QZS needs a lot of time for position stable time. However, QZSS positioning including QZS can get positioning for long time, more than GPS positioning only. For quantitative evaluation, it is necessary to analyze more data.

These results were shown in the positioning rate in Table 4. Table 4 shows that the average of the positioning rate of all experiments. GNSS positioning rate is the positioning time of GPS + QZS at the time of the GPS positioning time as $100 \%$.

\begin{tabular}{|c|c|c|c|c|c|c|c|}
\hline MASK & $30^{\circ}$ & $35^{\circ}$ & $40^{\circ}$ & $45^{\circ}$ & $50^{\circ}$ & $55^{\circ}$ & $60^{\circ}$ \\
\hline AVERAGE & $107 \%$ & $146 \%$ & $727 \%$ & $508 \%$ & $1779 \%$ & & \\
\hline
\end{tabular}

From Table, the effect of QZS if elevation mask of 30 degrees could not be obtained so much. However, more than 35 degrees elevation mask has shown that the positioning time is increased. In the table 4 , maximum value showed $2700 \%$. Also, when setting a higher elevation mask, the number of data can't be obtained. Therefore, additional experiments were conducted to confirm the effect of the QZS.

\subsection{Additional experiment}

Additional experiments were conducted in order to get more data. The experimental location and analysis method of additional experiment, the conditions of the experiment is the same as the previous experiment. Additional experiment was done about 30 times in October 2015. From Figure 15 to Figure20 indicates the results of the mask analysis about $30^{\circ}, 35^{\circ}$ and $40^{\circ}$. Experiments was carried out by cardinal direction. The vertical axis is a Japanese coordinate systems, the horizontal axis is time (UTC).

These figures indicates the results of the mask analysis. From Figure 10 to Figure 12 indicated GPS+ QZSS positioning has been carried out it is more time positioning than the GPS positioning. These figure indicates positioning time was reduced as it increases the elevation mask. In the case of 40 degrees, GPS positioning could not get position. Positioning including the QZS did not decrease possible time of measuring until 50 degrees. GPS positioning was impossible to get position when elevation mask is 40 degrees. Also, including the QZS needs a lot of time for stable positioning.

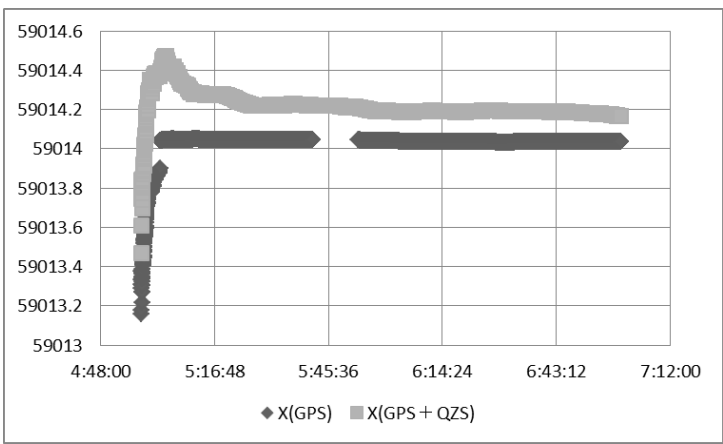

Figure15 Mask angle is 30 degrees (X direction) 


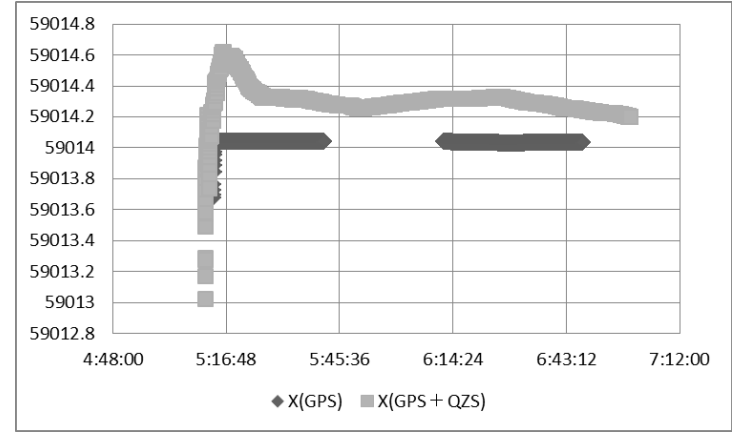

Figur16 Mask angle is 35 degrees (X direction)

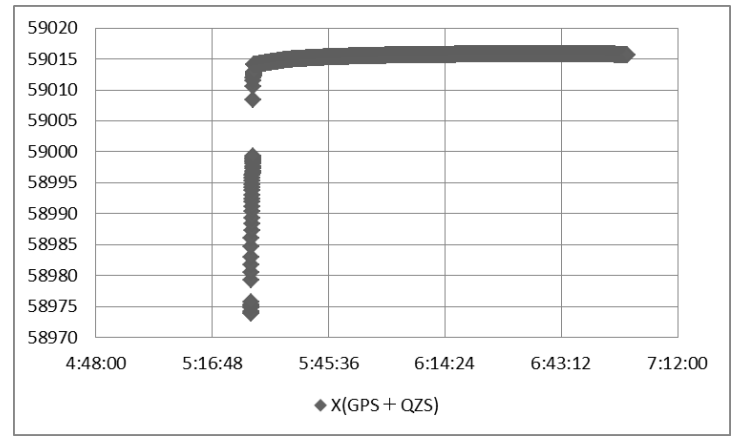

Figure17 Mask angle is 40 degrees ( $\mathrm{X}$ direction)



Figure18 Mask angle is 30 degrees (Y direction)

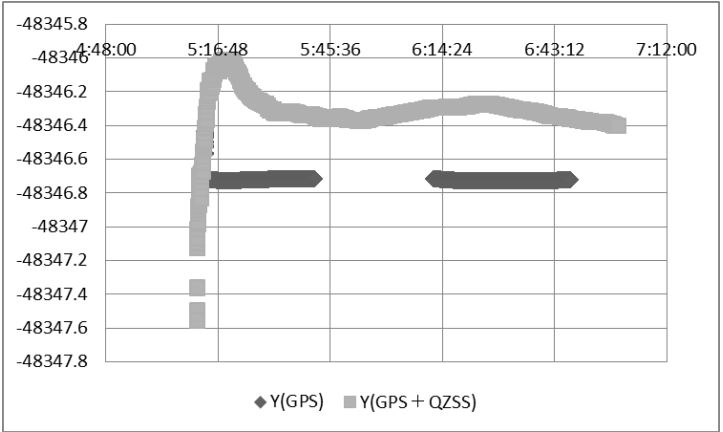

Figure19 Mask angle is 35 degrees (Y direction)

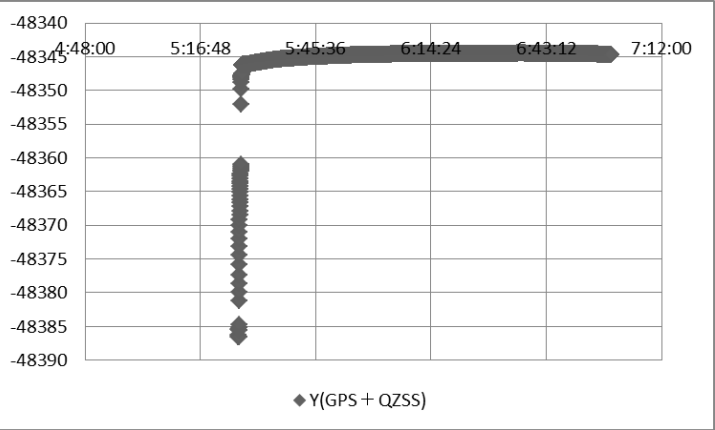

Figure20 Mask angle is 40 degrees (Y direction)

\begin{tabular}{|l|r|r|r|r|r|r|r|}
\hline $9 / 28 \mathrm{a}$ & $30^{\circ}$ & $35^{\circ}$ & $40^{\circ}$ & $45^{\circ}$ & $50^{\circ}$ & $55^{\circ}$ & $60^{\circ}$ \\
\hline $\mathrm{G}$ & 6573 & 3799 & 0 & 0 & 0 & 0 & 0 \\
\hline $\mathrm{G}+\mathrm{Q}$ & 7268 & 6483 & 5587 & 4026 & 1510 & 0 & 0 \\
\hline
\end{tabular}

Table 5 Result of positional time (s)

Table 5 indicated the positional possible hour every 5 degrees over 30 degrees. These data were carried out in September 28, 2015. From Table 5, trend of positioning time is decreasing as increase the elevation mask angle. As the reason of its, minimum required number of satellites was insufficient when elevation mask angle is increasing. Table 5 shows when the elevation mask was 30 degrees, there was no change in the positioning time. At elevation mask over 45 degrees, GPS positioning was impossible. In both experiments, QZSS positioning including QZS needs a lot of time for position stable time. However, QZSS positioning including QZS was able to get positioning data more than GPS positioning only. GNSS positioning rate was shown in Table 6 . Table 6 shows that the average of the positioning rate of all data.

\begin{tabular}{|c|c|c|c|c|c|c|c|}
\hline MASK & $30^{\circ}$ & $35^{\circ}$ & $40^{\circ}$ & $45^{\circ}$ & $50^{\circ}$ & $55^{\circ}$ & $60^{\circ}$ \\
\hline AVERAGE & $103 \%$ & $141 \%$ & $280 \%$ & $663 \%$ & $1262 \%$ & $2701 \%$ & \\
\hline & Table 6 Ratio of positioning time
\end{tabular}

From Table 6, the effect of QZS at elevation mask of 30 degrees could not be obtained so much. But it can be seen that if positioning time set the elevation mask more than 35 degrees is increasing. Elevation mask set more than 55 degrees was not possible to obtain a positioning solution. Positioning time is greatly affected by the satellite constellation.

\subsection{Second experiment}

First experiments to get Mask influence of GPS and QZSS was mentioned above. From the results of the first experiments, we scheduled the Second experiments from September to October in 2015.

From Figure 22 to 33 indicates plane-rectangular coordinates of $\mathrm{X}$ direction, $\mathrm{Y}$ direction and $\mathrm{Z}$ direction. Symbol of $(\mathrm{G})$ is only GPS and (GQ) is GPS+ GNSS. Symbol of "a" and "b" shows the type of receiver.

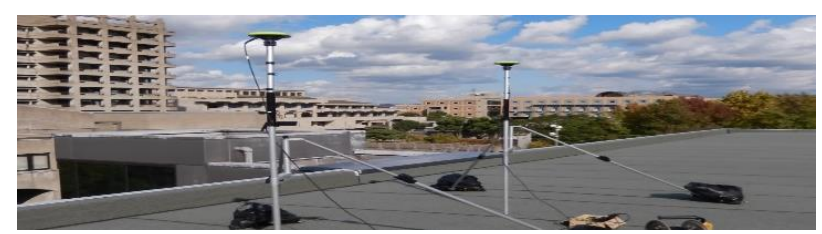

Figure 21 Experimental location of Second Experiments 


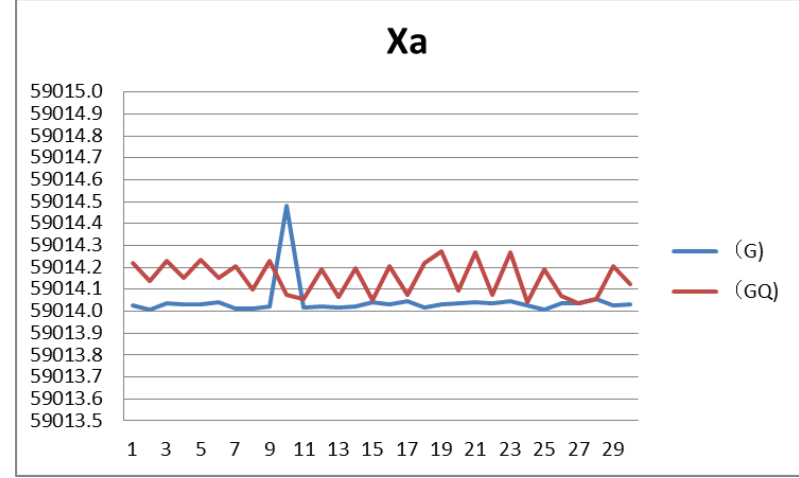

Figure22 Average of plane-rectangular coordinates for X direction of receiver "a"

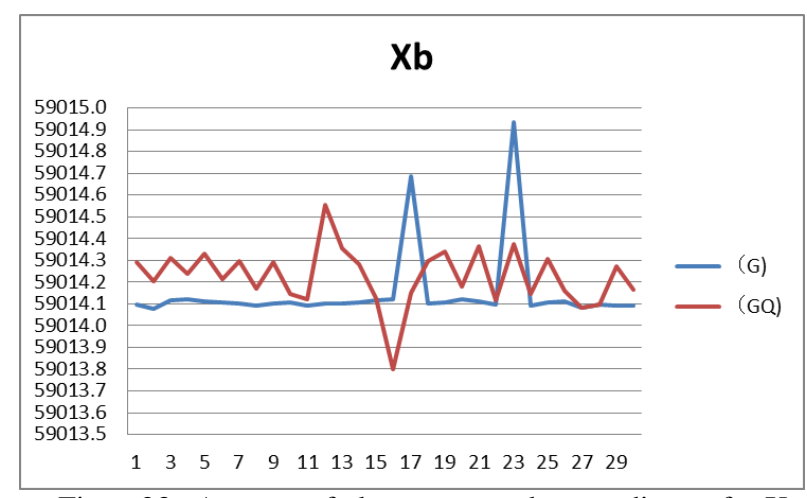

Figure23 Average of plane-rectangular coordinates for X direction of receiver "b"

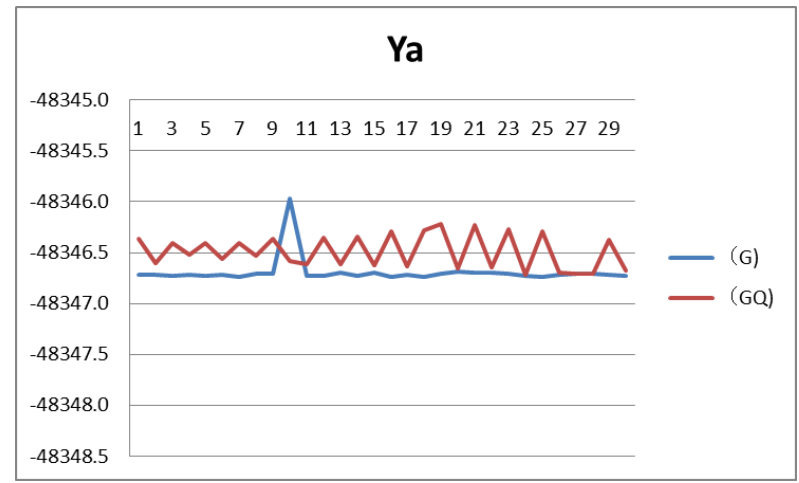

Figure24 Average of plane-rectangular coordinates for $\mathrm{Y}$ direction of receiver "a"

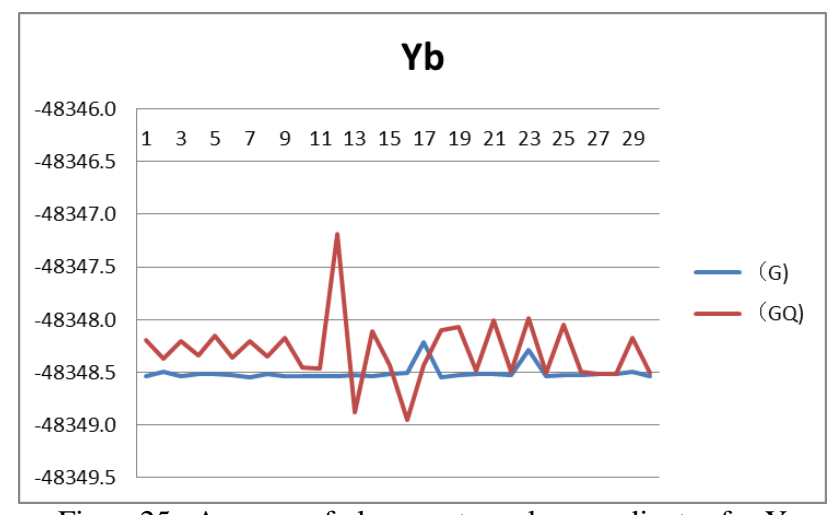

Figure25 Average of plane-rectangular coordinates for $\mathrm{Y}$ direction of receiver " $b$ "

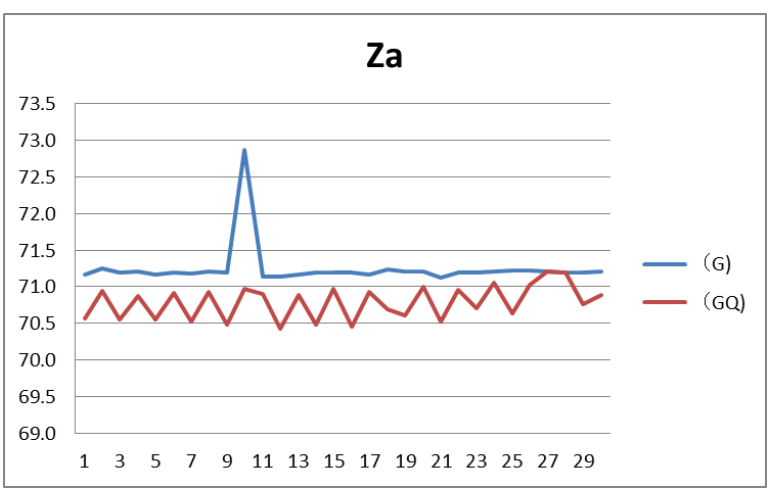

Figure26 Average of plane-rectangular coordinate for $\mathrm{Z}(\mathrm{m})$ direction of receiver "a"

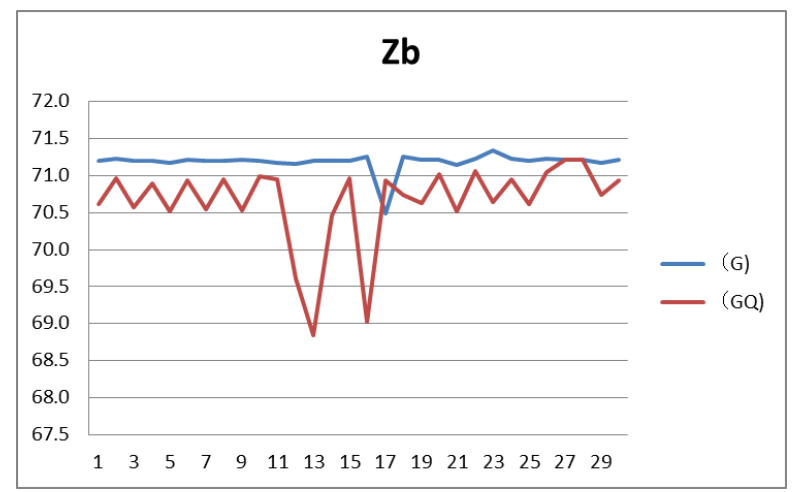

Figure27 Average of plane-rectangular coordinate for $\mathrm{Z}(\mathrm{m})$ direction of receiver " $b$ "

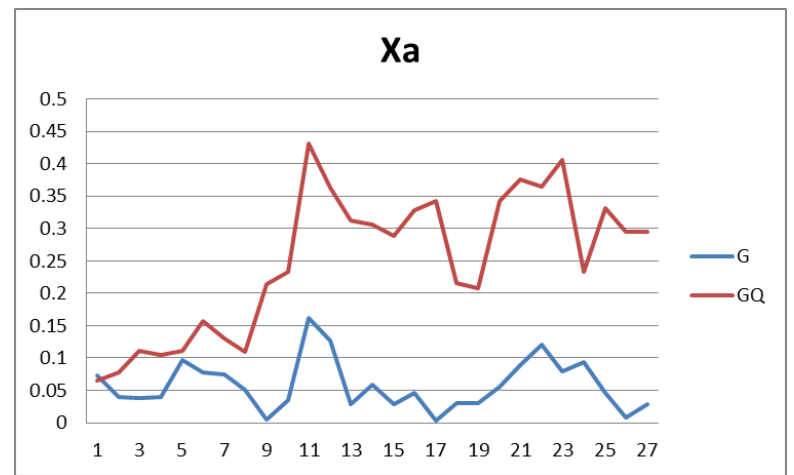

Figure28 Standard deviation of plane-rectangular coordinates for $\mathrm{X}$ direction of receiver " $\mathrm{a}$ "

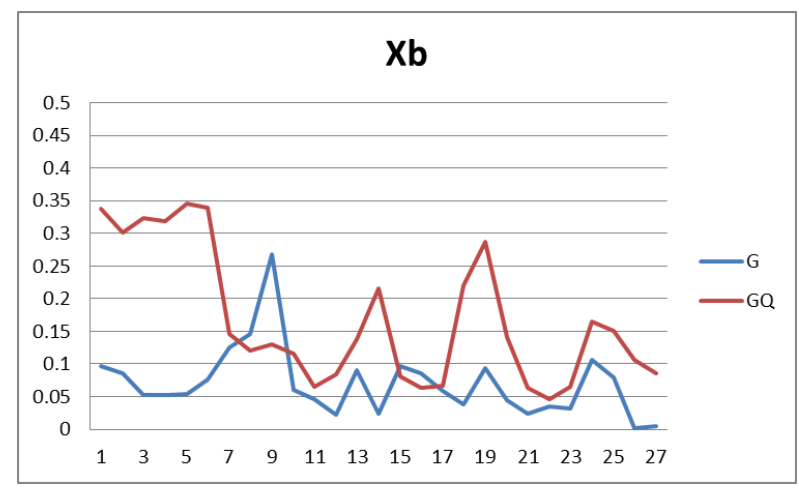

Figure29 Standard deviation of plane-rectangular coordinates for $\mathrm{X}$ direction of receiver " $\mathrm{b}$ " 


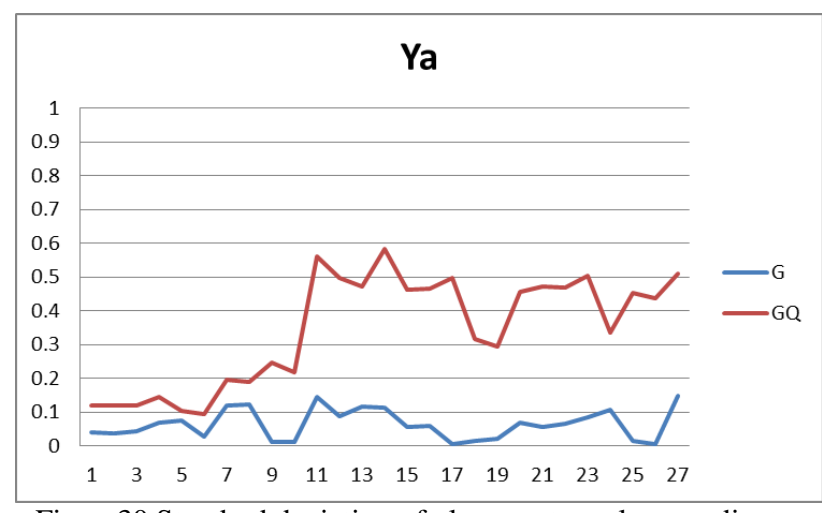

Figure30 Standard deviation of plane-rectangular coordinates for Y direction of receiver "a"

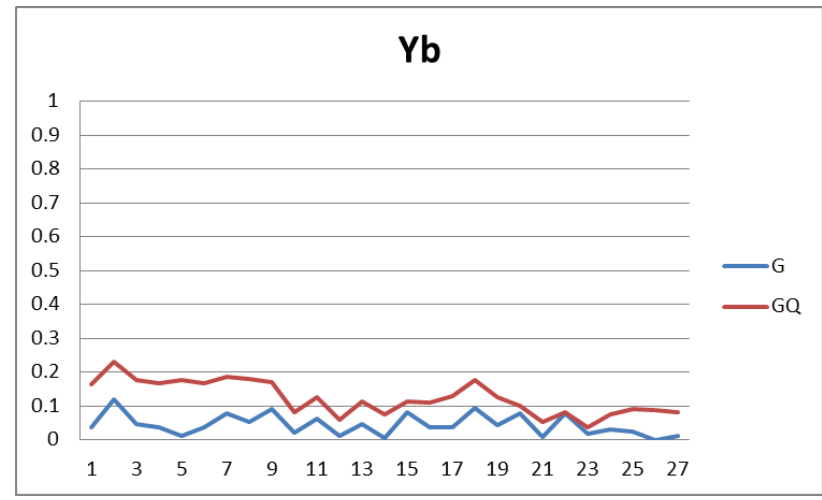

Figure31 Standard deviation of plane-rectangular coordinates for Y direction of receiver " $b$ "

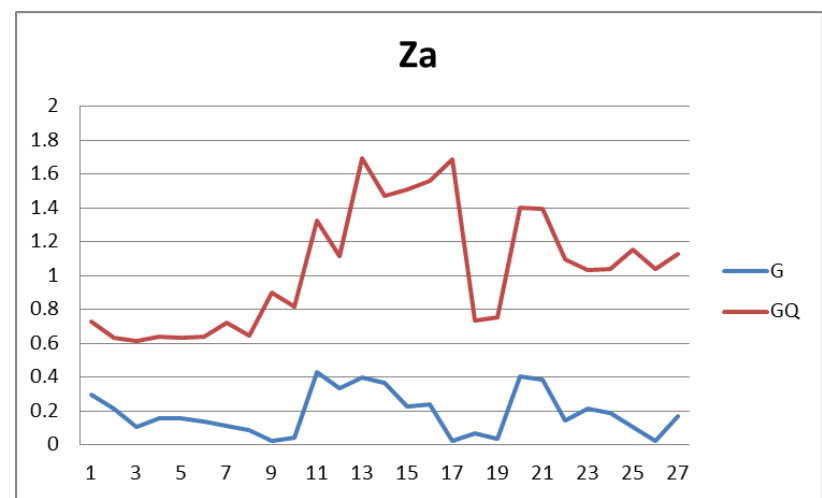

Figure32 Standard deviation of plane-rectangular coordinates for $\mathrm{Z}$ direction of receiver "a"

Zb

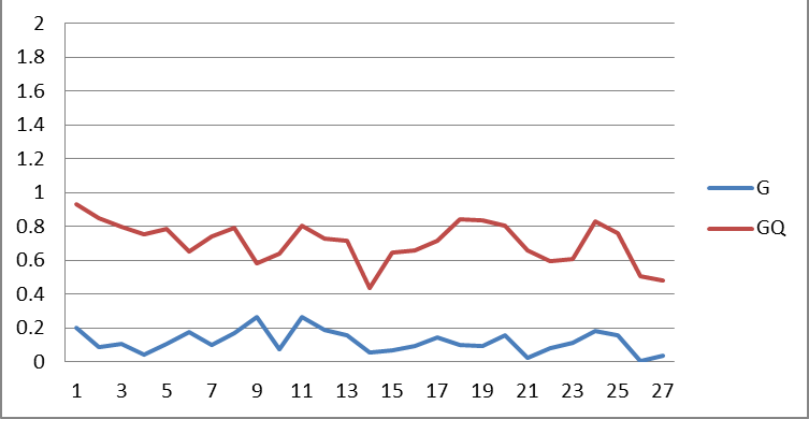

Figure33 Standard deviation of plane-rectangular coordinates for $\mathrm{Z}$ direction of receiver " $\mathrm{b}$ "
From Figure 22 to 27 indicates average of plane-rectangular coordinate, and from Figure 28 to 33 indicates standard deviation of plane-rectangular coordinates.

Relating with average, GPS has stable condition but GPS+QZSS has not stable than GPS. This is the reason GPS needs long time until stable first analysis. Relating with standard deviations, GPS has stable condition than GPS+QZS. This is same reason for average analysis.

\section{CONCLUSIONS}

We conducted experiments to investigate the complementary effect of the Quasi-Zenith Satellite which are the position changes and the possible time of positioning by including QZS. First, in case of comparison between GPS and GPS plus QZS, the difference between the average value of the GPS positioning and QZS plus GPS were few centimeters. Positioning data of only GPS was almost stable. Positioning including the QZS data had a larger variable positioning data. Second, in case of changing the elevation mask, possible time of positioning was decreased as increasing the elevation mask both positioning systems. However, GNSS positioning including the QZS needed more long positioning time than GPS positioning only. Satellite positioning should be conducted in better environments, which are the good DOPs and place of receiving signals from many satellites. But signal receiving time of QZS was restricted in this experiment. Therefore it was difficult to consider the surrounding environment such as DOP and satellite number. If QZS increases in the near future, it will be able to select a wide experimental environment. To quantitatively evaluate the positioning including the QZS, this experiment is not sufficient in the present condition.

Few years later, we will be able to conduct more experiments to verify the complementary effect of the QZS.

\section{FUTURE VIEW}

QZS system will have 4 satellites until 2018. Table 7 shows the plan of QZSS in the future.

\begin{tabular}{|l|c|c|c|}
\hline Period & $\begin{array}{c}\text { Number of } \\
\text { Satellite(Any } \\
\text { time receive } \\
\text { signals) }\end{array}$ & GPS & QZSS \\
\cline { 1 - 1 } Before 2017 & 6 to 8 & \multirow{2}{*}{31} & 1 \\
\hline 2018 to 2022 & 8 to 10 & & 3 \\
\hline After 2023 & 10 to 12 & & 5 \\
\hline
\end{tabular}

Table 7 Plan of QZSS for future

http://qzss.go.jp/overview/services/sv01_what.html

In the near future, satellite of QZS comes always existing in the Japanese sky. It's desirable that more than 8 satellites are seen for stable highly precise position estimating. In 2018, 4 zenith satellites will ready to a system, and more than 8 satellites merge with a GPS, and start to cover Japanese whole mostly. It's possible to get stable position information at the city and mountainous area. Geographic Survey of Japan has been offering observational data of GPS, GLONASS and QZS from 2012. QZSS can be able to give exact positioning data on surveying, information-construction and the IT agriculture.

\section{ACKNOWLEDGEMENTS}

The authors would like to thank to Shigeru Matsuoka, Natsuki Kondo and Koki Asari of SPAC (Satellite Positioning Research and Application Center), which give us advice of the paper and the experiment. In addition, we're thankful especially that you 
lent me JAVAD TR G3T ALPHA and LEXR.

Our laboratory member helps to get the data at the outside experiments from 2014 to 2016. They powerful work brought many data and useful analysis. The authors would like to thank to them too.

\section{REFERENCES}

S. Sugimoto and R. Shibasaki, GPS hand book, pp.258-273

Bernhard Hofmann-Wellenhof, Herbert Lichtenegger, and Elmar Wastle, GNSS-Global Navigation Satellite Systems GPS, GLONASS, Galileo, and more, Springer Wien New York, pp.338-342, 2008

M.Shikada,S.Shiraishi and S.Takeuchi,THE METHOD TO OBTAIN POSITION USING GNSS AND RFID FOR REALIZATION OF INDOOR AND OUTDOOR SEAMLESS POSITIONING; International Archives of the Photogrammetry, Remote Sensing and Spatial Information Science (ISPRS),Vol.36,B4,pp.45-50,2012

S.Shiraishi and M.Shikada,;On the demonstrated experiment using LEX signal from Quasi-Zenith Satelite in Hokuriku District; Asian Conference of Remote Sensing (ACRS),Proceedings(CD-ROM),PS2-40;2012

H. Munekane,Y. Kuroishi, Y.Hatanaka : Development of satellite positioning system simulator, Geospatial Information Authority of Japan Times 2008 No.115

Hiromune Namie, Fan, Chunming, A.Yasuda: A study on the optimal satellite mask angle of elevation in the GPS alone positioning, Institute of Electronics, Information and Communication Engineers Journal B vol.J89-B No.7

M.Shikada and S.Shiraishi, Evaluation of positioning characteristics using the LEX signal of the quasi-zenith satellite, Japan Society of Photogrammetry and Remote sensing Journal

N.Sekiguchi and M.Shikada, Experiments of the High Accuracy Positioning by Quasi -Zenith Satellite MICHIBIKI of Japan,ACRS2014(Asian conference of Remote Sensing).

http://qzss.go.jp/overview/services/sv01_what.html

(2.April

\section{APPENDIX}

In this paper, mask analysis was used RTKLIB ver2.4.2 by Tokyo University of Marine Science and Technology. One of the operational page is below.

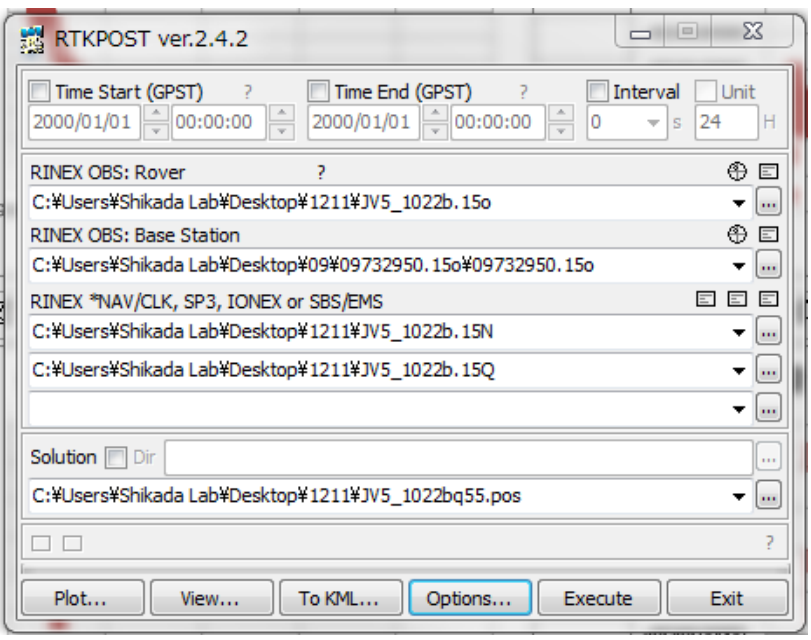

RTKPOST ver2.4.2 (Operational Page)

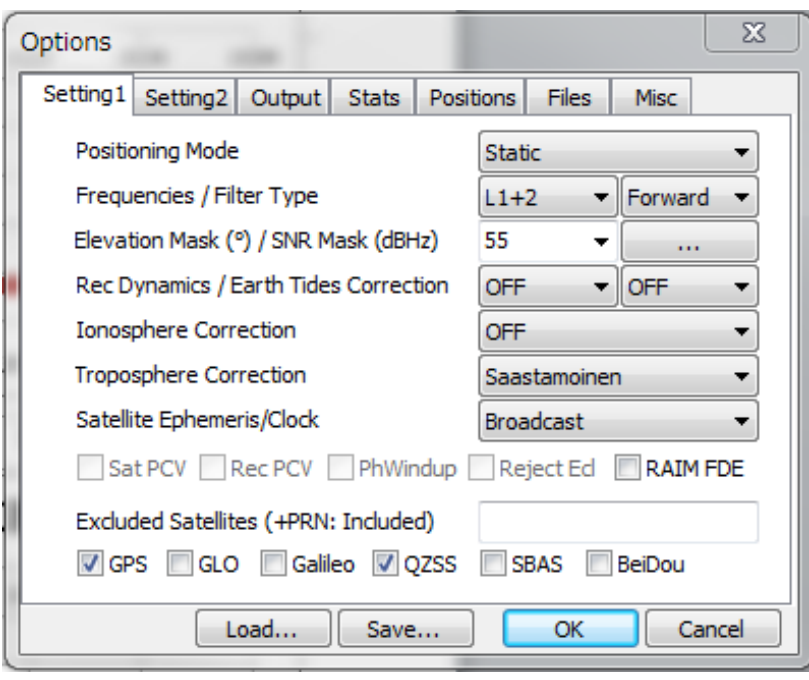

RTKPOST ver2.4.2 (Operational Page for Angle of Elevation) 2016) 